\title{
ICT Proficiency of Dental Students in Sri Lanka
}

Prof. J.U.Weerasinghe BDS, MS, PhD

Professor in Oral \& Maxillofacial Surgery, Faculty of Dental Sciences, University of Peradeniya, E-Mail address: juw@pdn.ac.lk

Dr. P Wijekoon BDS, MS

Senior Lecturer, Department of Oral \& Maxillofacial Surgery Faculty of Dental Sciences, University of Peradeniya,

E-Mail address: pwijekoon@yahoo.com

Sri Lanka Journal of Bio-Medical Informatics 2011;2(3):107-111

DOI: http://dx.doi.org/10.4038/sljbmi.v2i3.3796

\begin{abstract}
The Faculty of Dental Sciences, University of Peradeniya has been conducting formal introductory courses in ICT for undergraduates at their entry level. Although senior students do not get an opportunity for ICT education they will be required to perform tasks such as assignments, reports, referencing using ICT tools.

Dental undergraduates' proficiency in ICT was tested on randomly selected groups from three senior batches. Total performance of all students tested showed that the MCQ score (53.4, SD 8.0) has exceeded the pass mark and practical test (44.0, SD 7.2) has recorded well below. Individual tests on the practical components also showed that students were extremely weak in M S Excel (8.1, SD 2.2) and well below pass mark in M S Word (16.9, SD 2.9) and Powerpoint (19.0, SD 5.3) tasks.

This indicates that considering the basic nature of the questions in this ICT proficiency test, students have displayed a low level of skill in the practical component. However, the total aggregate for the overall student performance (48.8, SD 5.4) has recorded just below the pass mark of 50\%. These results reiterate the need for development of a formal supplementary training course in ICT for students in senior batches in the Faculty of Dental Sciences.
\end{abstract}

Keywords - ICT Proficiency; Dental Students; Sri Lanka

\section{Introduction}

Being the only institution in Sri Lanka conducting undergraduate and postgraduate education in dentistry and allied disciplines, from its commissioning of the new building complex in 1998, the Faculty of Dental Sciences, University of Peradeniya achieved University LAN access, an intranet for patient records with computer laboratory and CAL room for student use although the number of computer units were far below the requirements. From 2009, a formal short course in computer application was initiated in collaboration with the University IT Centre targeting the new entrants during their English language course. The Faculty has conducted two studies on ICT awareness by its students.

Online courses were considered as an option for providing distance education in dentistry $^{(1)}$. Students seem to consider the e-courses supplementing traditional methods of learning in the dental undergraduate programme ${ }^{(2)}$. A survey carried out in 2000 has revealed that computer use seemed to be lower than that in the developed countries $^{(3)}$. A questionnaire based survey ${ }^{(4)}$ conducted in 2009 among students (new entrants and first through fourth year batches, academic and non-academic staff) has revealed that among students. 
About $88 \%$ of have used computers before entering university, majority of senior students $(97.9 \%)$ use computers, students give priority to CAL CD (44.8\%) and internet downloading (73.8\%) as e-learning methods. Majority of academic staff used computers for academic work (90.9\%). Majority of participants from all groups studied have expressed that it is possible to carryout e-learning in Dentistry curriculum in the faculty.

These results indicate that the present groups of students and staff of the faculty will be ready to accept ICT programmes. However, in 2010 with the introduction of University Development Grant scheme with promoting ICT skills as one of the objective it was necessary to study the ICT proficiency among students which would help to design supplementary ICT programmes and for the periodical evaluation.

Assessment of ICT proficiency could be performed using awareness studies based on questionnaire surveys or actual examinations. The International Computer Driving Licence (ICDL) provided by the ECDL Foundation (www.ecdl.org/) is the gold standard to assess the ICT knowledge and competence. Developed countries have placed ICT skill benchmark at $60 \%$. In Sri Lanka CDL test is offered by National Apprentice and Industrial Training Authority (www.naita.slt.lk/) which consists of an ICT theory and practicals in MS office applications. The marking scheme considers weighted average for theory and practicals.

An ICT proficiency examination similar to SLCDL on a sample of randomly selected dental students was carried out in 2010 at the Faculty of Dental Sciences. Results were analysed to identify the student performance.

\section{Methodology}

\section{Format of the ICT examination}

The examination covered basics of hardware, software and commonly used Microsoft office applications (Word, Excel and Powerpoint) with a question paper consisting of 30 MCQs within 30 minutes and a practical session of 30 minutes consisting of exercises in the following.

MS WORD: retrieving a short paragraph from the server for editing and formatting

MS EXCEL: generating a worksheet and calculate tasks such as SUM and AVERAGE for given values

MS POWERPOINT: creating a slide in a presentation with title, text boxes and arrows for a given design

Marking scheme: Theory question paper: 50\% and Practical: 50\% (Word $=40 \%+$ Excel $=20 \%+\mathrm{PPT}=40 \%$ ). Pass mark $50 \%$ of the total aggregate (Theory+Practical)

Examination was held on 24 March 2010 in the Faculty CAL room which is equipped with 10 desktops with a server. Both authors participated in conducting the examination assisted by non-academic staff. 


\section{Selection of candidates:}

Students were informed at the beginning of the week regarding the importance of ICT development in the faculty and the need for an examination to evaluate the present status of knowledge of ICT among students. A notice from the Dean indicating the details of the ICT test was displayed a day before the test with the name list of 32 students randomly selected (using online resource-http://stattrek.com) eight each from the four batches.

\section{Results:}

Only 20 students turned up for the examination which included seven from the second year (2007 entrants), six from the third year (2005 entrants) and seven from the final year (2004 entrants). Results are discussed in relation to performance of student groups in relation to examination, its components and mean student score.

Fig 1. Performance of student groups for MCQ and Practicals

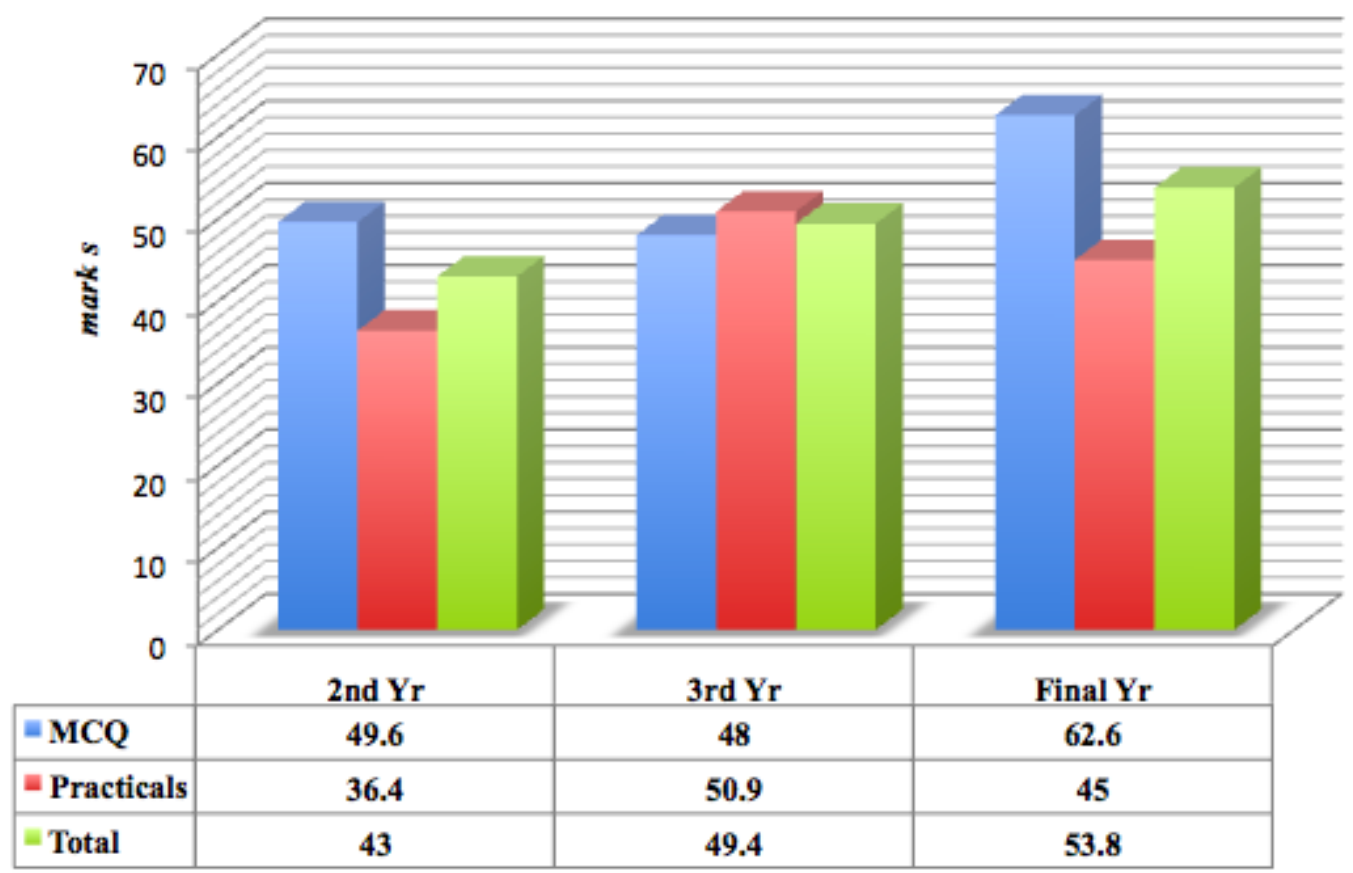

Figure 1 describes mean values for MCQ and practical examination components out of 100 marks were recorded as 49.6 (SD 13.3) and 36.4 (SD 24.6) for the second year, 48.0 (SD 18.0) and 50.9 (SD 19.3) for the third year, 62.6 (SD 16.8) and 45.0 (SD 17.3) for the final year respectively. Total aggregate mean values recorded for three groups were 43.0 (SD 17.7), 49.4 (SD 18.5) and 53.8 (SD 22.9). 
Fig 2. Performance of student groups for practical session components

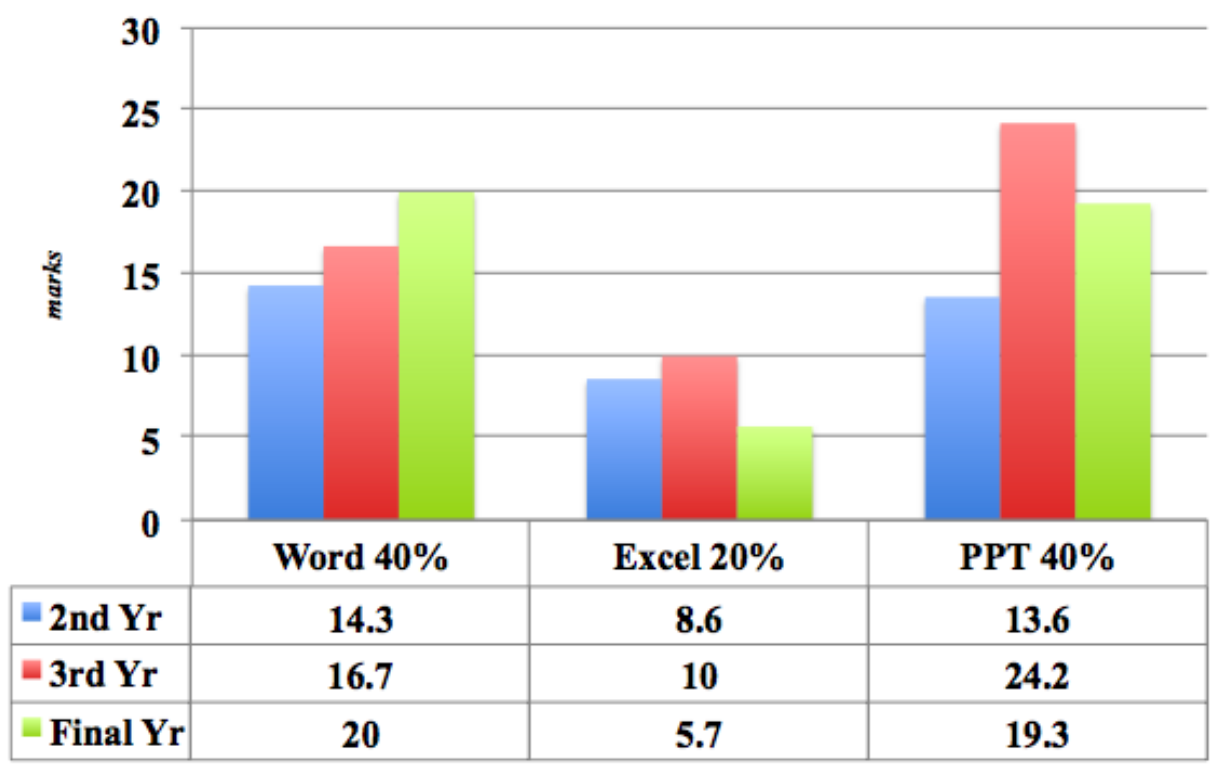

Regarding the practical examination component Figure 2 describes mean values for Powerpoint (40 marks), MS Excel (20 marks) and MS Word (40 marks) were recorded as 14.3 (SD 12.1), 8.6 (SD 9.0), 13.6 (SD 14.9) for the second year, 16.7 (SD 10.3), 10.0 (SD 11.0), 24.2 (SD 9.7) for the third year and 20.0 (SD 5.8), 5.7 (SD 7.9), 19.3 (SD 13.4) for the final year.

Fig 3. Mean student performance

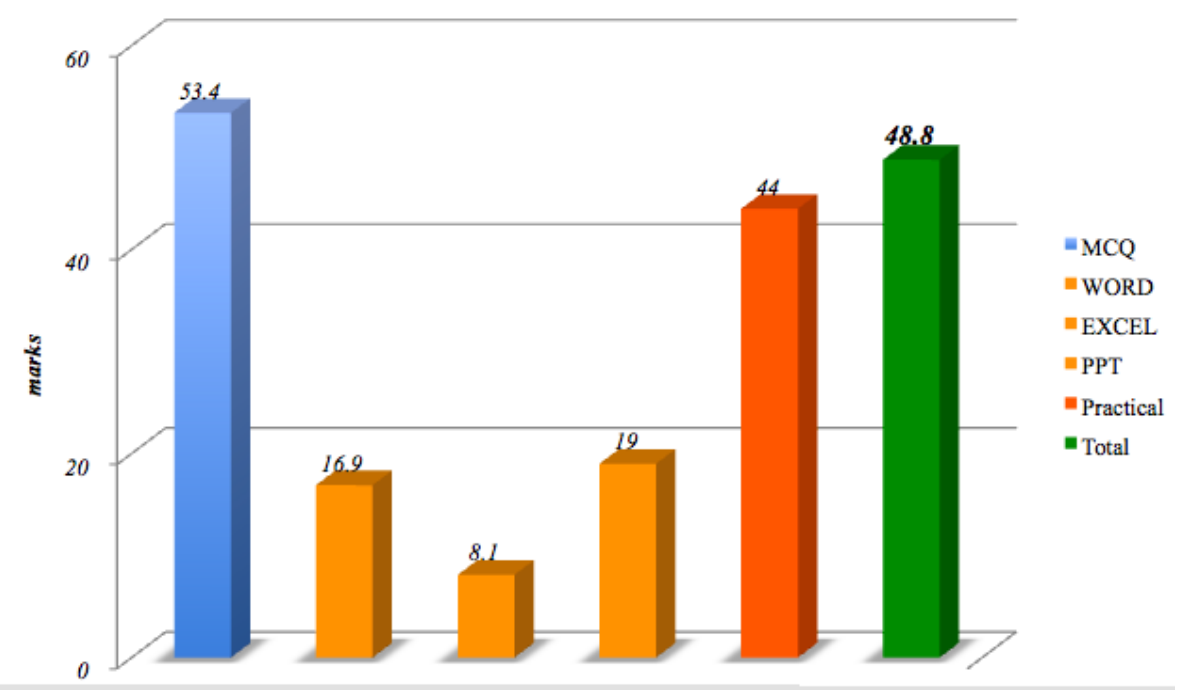

Figure 3 describes results for all student groups tested which revealed that mean values were recorded as 53.4 (SD 8.0) for the theory examination (MCQ) and 44.0 (SD 7.2) for the practical examination. In the practical examination means for MS Word, MS Excel and Powerpoint were 16.9 (SD 2.9), 8.1 (SD 2.2) and 19.0 (SD 5.3) respectively. The mean total for all students were 48.8 (SD 5.4). 


\section{Discussion}

Out of 20 students randomly selected from three batches, for the MCQ component, Final year students (mean score 62.61, SD 16.8) have exceeded the pass mark while second (49.58, SD 13.3) and third years (48.04, SD 18.0) have performed just below. For the practical examination, third year students (mean score 50.83, SD 19.3) have just reached the pass mark while second (36.43, SD 24.6) and final year students (45.0, SD 17.3) have scored below.

Total performance of all students tested also showed that the MCQ score (53.41 \pm 8 ) has exceeded the pass mark and practical examination results $(44.09 \pm 7.2)$ were well below. Individual tests on the practical tasks also showed that students were extremely weak in MS Excel $(8.10 \pm 2.2)$ and well below the pass mark in MS Word $(16.98 \pm 2.9)$ and Powerpoint1 (19.01 \pm 5.3$)$.

This indicates that considering the nature of the questions in this ICT proficiency test, students have displayed a low level of skill in the practical examination. However, the total aggregate for the overall student performance (48.75 \pm 5.4$)$ has recorded just below the pass mark of $50 \%$.

These results reiterate the need for development of a formal training course in ICT in the Faculty of Dental Sciences.

\section{References}

1. Grimes EB. Student perceptions of an online dental terminology course. J Dent Educ 2002; 66-1:100-7- PMID:12358096

2. Gupta B, White DA, Walmsley AD. The attitudes of undergraduate students and staff to the use of electronic learning. Br Dent $J$ 2004; 196:487-492 doi:10.1038/sj.bdj.4811179

3. Wijekoon P. Survey of the Computer Literacy of Undergraduate Dental Students in Sri Lanka. Sri Lanka Dental Journal 2009; 39-3:63-67

4. Weerasinghe J.U, Siriwardena B.S.M.S. Awareness on e-Learning by students and staff of the Faculty of Dental Sciences. Proceedings of the Peradeniya University Research Sessions, Sri Lanka 2009;14-II:608-10 